\title{
AKTIVITAS MAKAN BEKANTAN (Nasalis larvatus) DI HUTAN MANGROVE DESA NIPAH PANJANG KECAMATAN BATU AMPAR KALIMANTAN BARAT
}

\author{
(Feeding Activities of Proboscis Monkey (Nasalis larvatus) on Mangrove Forest in Nipah \\ Panjang Village Batu Ampar District West Kalimantan Province)
}

\author{
Aghisti Yokassye, Slamet Rifanjani, Muflihati \\ Fakultas Kehutanan, Universitas Tanjungpura, Jalan Imam Bonjol Pontianak 78124 \\ e-mail: ayokassye@gmail.com
}

\begin{abstract}
Proboscis monkey feeding activity is activity associated with the fulfillment of the energy needed to maintain the viability of the proboscis. Such activity includes search activity feed, feed selection, behavioral feed entering into the mouth, chewing and swallowing followed. Proboscis is the dominant species, which means folivora feed on the leaves, but sometimes also can feed on flowers and fruit on a small scale. The purpose of this study was to record the feeding activity in Mangrove Forest Village proboscis monkeys Nipah Panjang Batu Ampar District of West Kalimantan using focal animal research methods of sampling and analyzed using qualitative descriptive analysis. The results showed proboscis start feeding activity at $05.00 \mathrm{pm}$ with pemuncakan time at $07.00 \mathrm{pm}$ and $15.00 \mathrm{pm}$ to feeding behavior that is looking for a large tree limb then sat down and took this feed by way of picking and pulling. The position of the male proboscis monkey eating is always the top and back while females move proboscis at the front leading the group movements during foraging. Percentage feeding activity on the proboscis male is larger than the proboscis females is 33\% while the proboscis females is $31 \%$ while for the type of feed, there are 7 species of plants which feed the proboscis with the plant is the most widely consumed is leafs
\end{abstract}

Keywords: Proboscis Monkey, Feeding Activities, Behavior, Type of Feed, Nipah Panjang

\section{PENDAHULUAN}

Bekantan (Nasalis larvatus) merupakan satwa endemik Kalimantan dengan status vulnerable (berisiko tinggi terancam punah dalam waktu tidak terlalu lama lagi) oleh IUCN dan Appendiks I (tidak boleh diperdagangkan secara internasional) oleh CITES (Soendjoto, 2002). Aktivitas makan bekantan adalah aktivitas yang berhubungan dengan pemenuhan kebutuhan energi yang dibutuhkan untuk menjaga kelangsungan hidup bekantan. Bekantan memulai aktivitas makannya rata-rata pukul 05:30 WIB ada jeda waktu \pm 20-30 menit untuk bekantan bergerak mencari pohon pakannya. Perilaku makan pada bekantan yaitu memanjat pohon yang tinggi dan memilih cabang pohon yang besar untuk kemudian duduk dan mencari pakannya. Posisi bekantan jantan akan selalu paling atas dan paling belakang diantara anggota kelompok lainnya hal ini dilakukan karena bekantan jantan yang bertugas memantau dan mengawasi anggota kelompoknya sementara betina yang paling depan dengan memimpin pergerakan anggota kelompoknya. Bekantan merupakan primata folivora (dominan memakan daun) yang bisanya mengkonsumsi daun muda. Penelitian ini 
dilakukan bertujuan untuk mendata aktivitas makan bekantan di Hutan Mangrove Desa Nipah Panjang Kecamatan Batu Ampar Kalimantan Barat.

METODE PENELITIAN

Penelitian ini dilakukan di Desa Nipah Panjang Kecamatan Batu Ampar Kabupaten Kubu Raya Provinsi Kalimantan Barat selama 15 hari pada 09 november - 24 november 2018dengan menggunakan metode Focal Animal Sampling yaitu pengamatan dengan fokus pada satu objek pengamatan untuk mengamati aktivitas makan bekantan. Objek pengamatan ini ialah satu bekantan jantan dewasa dan satu bekantan betina dewasa. Pengamatan di mulai dari pukul 05.0019.00 WIB dengan interval pengamatan selama 5 menit. Data yang diambil berupa aktivitas yang meliputi aktivitas makan dan waktu makan, jenis tumbuhan dan bagian-bagian yang dimakan oleh bekantan kemudian data diolah menggunakan analisis deskriptif kualitatif.

\section{HASIL DAN PEMBAHASAN}

Bekantan memulai aktivitas makannya pada pukul 05:30 WIB terdapat jeda waktu \pm 20 -30 menit dari bangun tidur yang digunakan bekantan untuk bergerak mencari pohon pakan. Pergerakan bekantan dilakukan secara berkelompok dari pohon tidur menuju pohon pakan yang dipimpin oleh bekantan betina, selain makan dan pergerakan terdapat satu aktivitas harian inti pada bekantan yaitu istirahat yang dipergunakan untuk memproses pencernaan makanan dan memulihkan tenaga seteleh seharian beraktivitas.

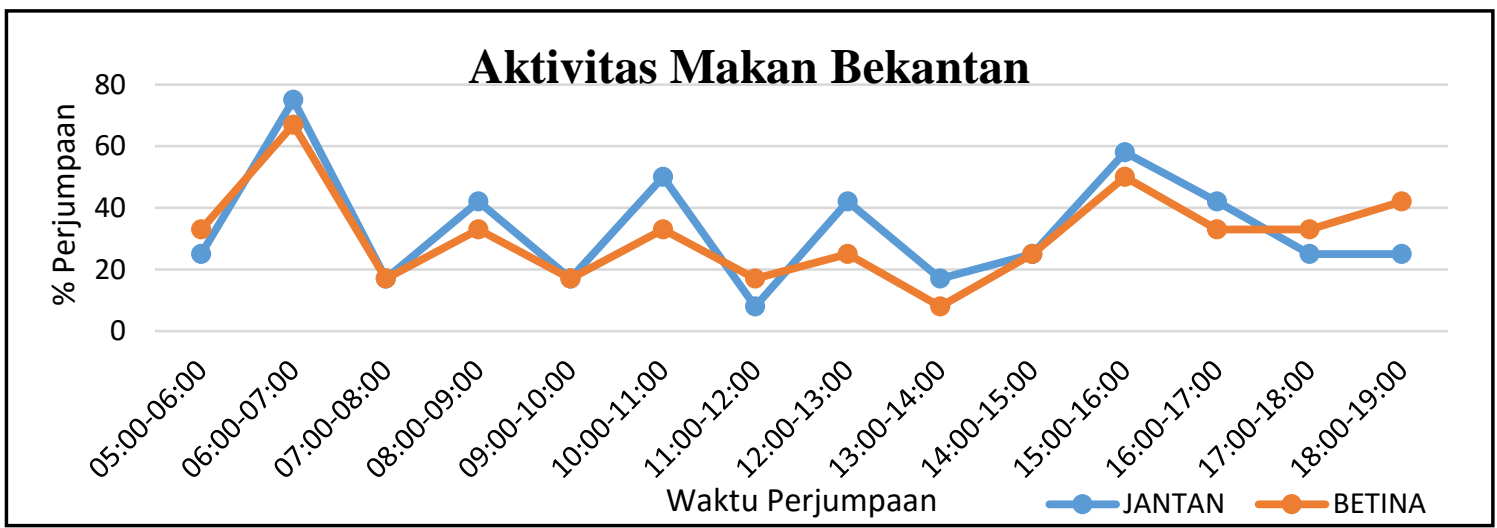

Gambar 1. Aktivitas Makan Bekantan (Feeding Activities of Proboscis Monkey)

Persentase perjumpaan tertinggi waktu makan bekantan terjadi pada pukul 06.00-07.00 WIBsebesar 75\% untuk bekantan jantan dan $67 \%$ untuk bekantan betina. Pemuncakan waktu makan pada pagi hari dikarenakan pada pagi hari bekantan mengkonsumsi makannya untuk menggantikan energi yang dikeluarkan saat mencerna pakan yang ia konsumsi sebelumnya dan juga untuk mengisi energi yang akan digunakan untuk menjalankan seluruh aktivitas kesehariaannya sedangkan pemuncakan pada sore hari dikarenakan pada waktu ini bekantan akan mulai mempersiapkan diri mencari pohon tidur sehingga membutuhkan energi yang 
lebih banyak. Saat sore hari bekantan akan mencari pohon tidur yang memiliki pakan yang dapat mencukupi kebutuhannya dikarenakan sebelum tidur bekantan biasanya memilih untuk makan menjelang waktu tidurnya. Bismark (1986) menyatakan bahwa aktivitas yang dilakukan bekantan pada pagi hari adalah makan yang berguna untuk mengisi kembali cadangan energi yang habis terpakai ketika beristirahat.Persentase aktivitas makan bekantan jantan dan bekantan betina mengalami pola yang sama dengan posisi yang berbeda. Hal ini dipengaruhi oleh jenis kelamin dan ukuran tubuh setiap individu yang berkaitan dengan pemenuhan jumlah energi untuk beraktivitas.

Aktivitas makan mengalami penurunan pada pukul 09:00-14:00 WIB. Hal ini terjadi karena bekantan mulai beristirahat pada pohon pakan. Selain itu, suhu udara yang mulai tinggi juga menyebabkan bekantan lebih memilih menetap pada satu lokasi pohon dan hanya memakan yang ada disekitarnya. Alikodra et. al (2015) menyatakan bahwa penurunan persentase aktivitas makan pada periode siang dan sore hari terjadi sebagai dampak dari peningkatan aktivitas istirahat untuk menghindari kondisi ektrem di lingkungan dan karena bekantan harus menyimpan cadangan makannya untuk melakukan aktivitas pergerakan dan mencari pohon tidur. Menurut Alikodra (1997), bekantan mulai mencari pohon tempat tidur pada pukul 17.00 WIB bekantan memilih pohon tidur yang sekaligus mampu menyediakan pakan bagi mereka.
Posisi makan bekantan jantan akan selalu paling atas dan paling belakang diantara anggota kelompok lainnya hal ini dilakukan karena bekantan jantan yang bertugas memantau dan mengawasi anggota-anggota kelompoknya sementara betina akan selalu paling depan untuk memipin pergerakan makan kelompoknya. Perilaku makan bekantan yaitu memanjat pohon yang tinggi dan memilih cabang pohon yang besar untuk kemudian duduk dan mencari pakannya dimulai dengan memilih daun-daun yang akan dimakannya kemudian mengambil dengan mematahkan rantingnya, biasanya menggunakan tangan kanan tapi tak jarang pula juga menggunakan tangan kiri. Selanjutnya bekantan akan memilah bagian-bagian yang akan dimakannya, bekantan tidak selalu memakan seluruh bagian tumbuhan yang dipetik karena bekantan hanya mengkonsumsi pucuk daun atau daun mudanya saja. Hal ini diperkuat oleh pernyataan Bismark (1986) bahwa di hutan mangrove bekantan hanya memakan sebagian daun dan membuang sisanya. Cara ini merupakan upaya bekantan untuk mengefisiensikan energi dalam pencernaan pakan dan untuk memperoleh gizi yang lebih baik. Selanjutnya bekantan memasukan pakan kedalam mulut diikuti dengan mengunyah hingga menelan.

Bekantan memerlukan \pm 8-9 lembar daun untuk pakannya dalam sekali makan dan memasukan satu sampai dua lembar pucuk daun kemudian mengigitnya menjadi 2 lalu mengunyahnya $\pm 10-30$ kali. Buah dimakan satu per satu dan dikunyah 15-30 kali, sehingga dalam 5 
menit bekantan mengkonsumsi 7,5 buah. Selama pengamatan bekantan terlihat memakan bunga hanya 3 kali, mengigit bunga menjadi 2 lalu mengunyahnya selama $\pm 10-30$ kali. Bismark (1994) menyatakan bekantan memerlukan 15,6 buah untuk sekali makannya. Kegiatan mengunyah sebanyak 10-30 kali adalah salah satu strategi bekantan untuk membantu pencernaan secara fisik dan merangsang keluarnya air liur guna mempertahankan PH lambung agar proses fermentasi pakan oleh bakteri lambung dapat berjalan optimum.

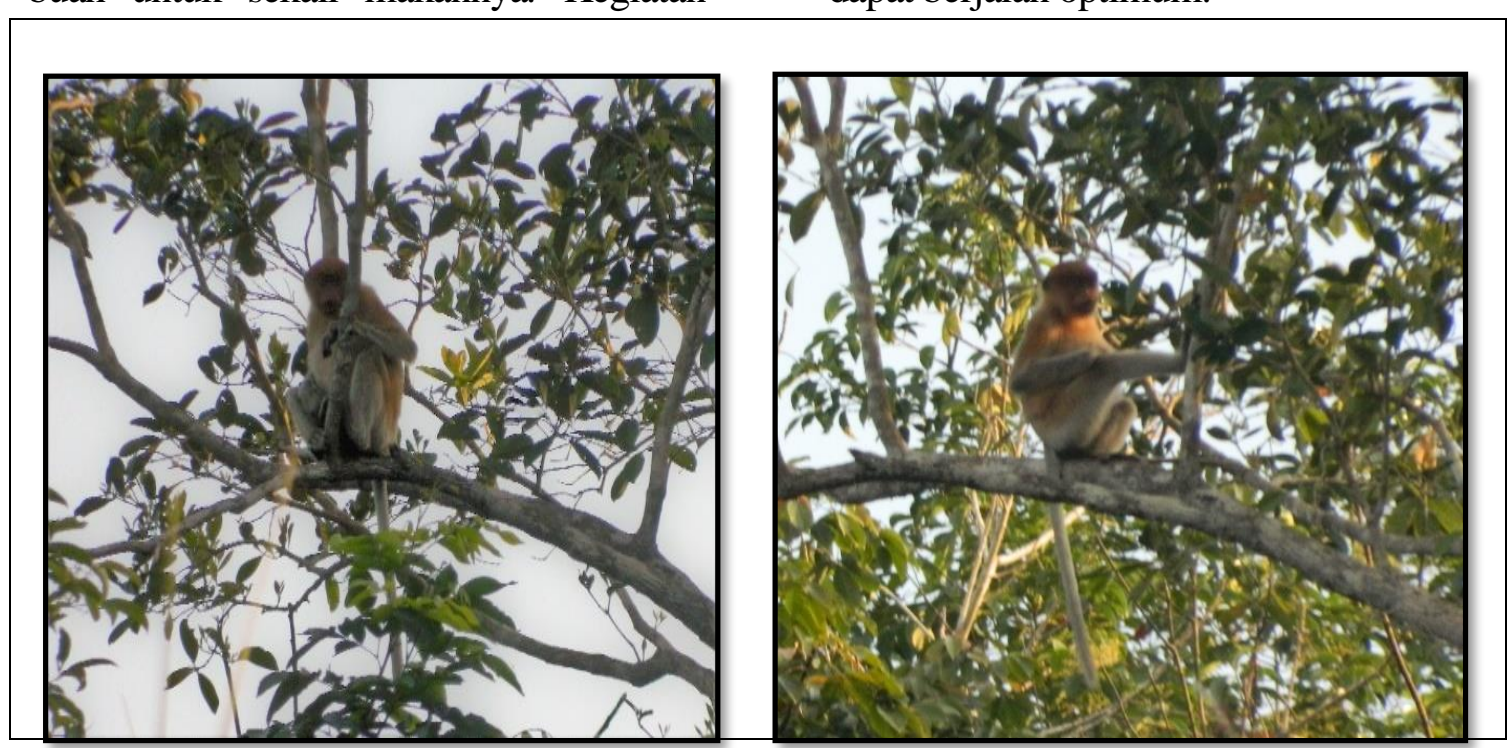

Gambar 2. Perilaku Makan Bekantan Jantan (kiri) dan Bekantan Betina (kanan) (Feeding Behavior Male Proboscis Monkey (left) and female (right)

Aktivitas makan bekantan berupa perilaku dan waktu makan antara jantan dan betina dewasa hampir sama, namun terdapat perbedaan pada posisi dan jumlah pakannya. Hal ini dikemukakan oleh Hendra, (2015) bahwa terdapat kesamaan perilaku makan namun berbeda pada posisi cara mengambil atau menggapai makanan oleh bekantan. Bekantan melakukan pengambilan bagian helai daun yang masih muda kemudian daun dimasukkan ke dalam mulutnya dan menghabiskan beberapa helai daun/buah/bunga. Setiap individu mampu menghabiskan 1-3 helai daun/buah/bunga. Bekantan melakukan pengambilan bagian daun muda dengan menarik batang yang menjalar dan memegang tangkai kemudian daun dimasukkan ke dalam mulutnya dan menghabiskan beberapa helai daun dalam sekali makan, untuk bagian bunga dan buah bekantan melakukan pengambilan bagian bunga atau buah dengan menarik batang yang menjalar, kemudian memegang tangkai bunga atau buah dan memasukkan kedalam mulutnya. 
Tabel 1. Jenis Pakan Bekantan di Hutan Mangrove Desa Nipah Panjang (Type of feed Proboscis Monkey on Mangrove Forest in Nipah Panjan)

\begin{tabular}{|c|c|c|c|c|}
\hline No & Nama Lokal & Nama Ilmiah & Famili & $\begin{array}{c}\text { Bagian } \\
\text { dimakan }\end{array}$ \\
\hline 1 & Bakau Merah & Rhizophora apiculata & Rhizophoraceae & Pucuk daun \\
\hline 2 & Nipah & Nypa fruticans & Arecaceae & Bunga \\
\hline 3 & Nyirih & Xylocarpus moluccenssis & Meliaceae & Pucuk daun \\
\hline 4 & Pakis merah & Stenochlaena palustris & Blechnales & Pucuk daun \\
\hline 5 & Ara & Ficus microcarpa & Moraceae & $\begin{array}{l}\text { Pucuk daun, } \\
\text { Buah }\end{array}$ \\
\hline 6 & Piai & Acrostichum aureum & Pteridaceae & Pucuk daun \\
\hline 7 & Tumuk Merah & Bruguiera gymnorrhiza & Rhizophoraceae & $\begin{array}{l}\text { Pucuk daun, } \\
\text { bunga }\end{array}$ \\
\hline
\end{tabular}

Jenis pakan bekantan yang ditemukan di hutan mangrove Desa Nipah Panjang Kecamatan Batu Ampar Kalimantan Barat sebanyak 7 jenis. Berdasarkan penelitian Kartono at al (2008) di tempat yang sama menemukan bahwa B. gymnorrhiza dan F. microcarpa merupakan jenis yang paling dominan dimakan oleh bekantan. Sedangkan menurut Bissmark (2013) bahwa B. gymnorrhiza, F. microcarpa dan $X$. moluccenssis merupakan jenis yang paling banyak dikonsumsi bekantan.

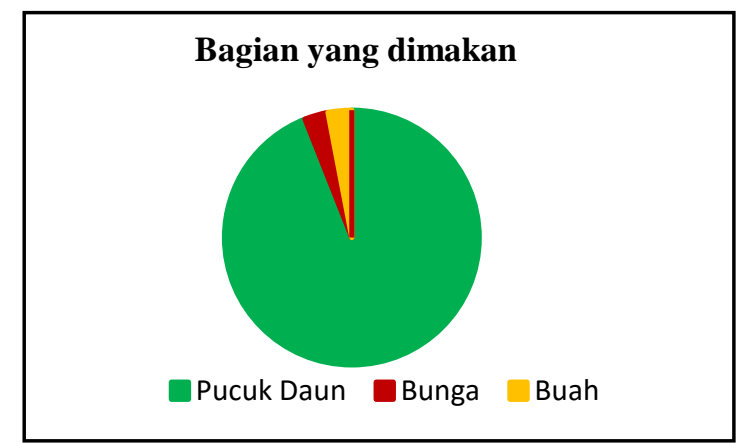

Gambar 3. Bagian-bagian tumbuhan yang dimakan bekantan (Part of plants that consumed by proboscis monkey)

Bagian tumbuhan yang menjadi pakan bekantan yaitu daun, bunga, dan buah, yang paling banyak dikonsumsi yaitu pucuk daun sebesar $94 \%$, sedangkan bagian bunga dan buah masing-masing sebesar 3\%. Hal ini dikarenakan bekantan merupakan primata yang tergolong Folivore yaitu pemakan daun (Supriatna dan Wahyono, 2000).Selain itu bekantan ditemukan lebih sering memakan pucuk atau daun muda daripada daun tua.Hal ini sesuai dengan pendapat Bennett dan Sebastian (1988) bahwa bekantan mengutamakan daun muda walaupun daun tua melimpah. Bekantan akan memakan daun tua apabila daun muda tidak tersedia lagi. Penyebab pemilihan daun muda ini adalah kadar airnya lebih banyak. Diketahui bahwa kadar air pada pucuk mencapai $88 \%$ dan pada daun muda $67 \%$. Bismark (1987) melaporkan bahwa di hutan mangrove bekantan memakan daun dengan kandungan air $68 \%$. Faktor lain adalah tingkat kemudahan untuk mencerna yang tinggi pada daun muda yang diindikasikan dari rendahnya serat kasar yang dikandung oleh pucuk atau daun muda.

\section{KESIMPULAN}

Dalam melakukan pengamatan dilapangan terhadap Aktivitas Makan 
dan Jenis Pakan Bekantan Di Hutan Mangrove Desa Nipah Panjang Kecamatan Batu Ampar Kalimantan Barat maka dapat diambil kesimpulan sebagai berikut :

1. Aktivitas makan bekantan jantan alpha dewasa dan bekantan betina dewasa terdapat banyak persamaan pada perilaku makan dan waktu makan akan tetapi memiliki perbedaan pada posisi makan dan presentase aktivitas makannya. Presentase aktivitas makan bekantan jantan dalam sehari mencapai 33\% dan bekantan betina memerlukan $31 \%$ untuk makan dalam sehari.

2. Terdapat 7 jenis tumbuhan yang menjadi pakan bekantan Bakau merah (Rhizophora apiculata), Nipah(Nypa fruticans), Nyirih (Xylocarpus mekogensis), Pakis merah (Stenochlaena palustris), Ara (Ficus microcarpa), Piai (Acrostichum aureum), dan Tumuk merah (Bruguiera gymnorrhiza). Tumbuhan pakan yang paling disukai oleh kategori bekantan jantan yaitu Tumuk merah(Bruguiera gymnorrhiza) dan bekantan betina Ara(Ficus microcarpa).Bagian-bagian tumbuhan yang menjadi pakan bekantan yaitu Daun (94\%), bunga $(3 \%)$, dan buah $(3 \%)$.

\section{SARAN}

Diperlukan penelitian lanjutan terhadap kehidupan bekantan terutama mengenai Perilaku, Jenis Pakan dan Komposisi Pakan agar dapat melengkapkan data-data informasi bekantan khususnya di Kalimantan Barat sehingga dapat dilakukan konservsi secara maksimal karena data dan informasi yang diperlukan telah tersedia dengan benar.

\section{DAFTAR PUSTAKA}

Bennett EL, Sebastian. 1988. Social organization and ecologyof proboscis monkeys (Nasalis larvatus) in mixed coastal forest in Sarawak. Int. J. of Primatol. 9 (3):233-255.

Bismark M. 1986. Perilaku bekantan (Nasalis larvatus) dalam memanfaatkan lingkungan hutan bakau di Taman Nasional Kutai, Kalimantan Timor. Thesis Magister Sains, Program Pascasarjana IPB, Bogor.

Bismark. 2009. Biologi Konservasi Bekantan (Nasalis larvatus). Pusat Penelitian dan Pengembangan Hutan dan Konservasi Alam. Bogor.

Kartono AP, Ginting A, Santoso N. 2008. Karakteristik Habitat Dan Wilayah Jelajah Bekantan Di Hutan Mangrove Desa Nipah Panjang Kecamatan Batu Ampar Kabupaten Kubu Raya Provinsi Kalimantan Barat. Media Konservasi 20 (3): 242-251.

Rugayah. Retnowati A. Windradi FI, Hidayat. 2004. Pengumpulan Data Taksonomi. Pusat Penelitian LIPI. Bogor.

Supriatna J, Edy H. 2000. Panduan Lapangan Primata Indonesia, Yayasan Obor Indonesia. Jakarta.

Wirdateti, Pratiwi AN, Diapari D, Anita S, Tjakradidjaja. 2009. Perilaku 
JURNAL HUTAN LESTARI (2019)

Vol. 7 (3) : 1140 - 1146

harian lutung (Trachypithecus

cristata, Raffles 1821) di

penangkaran pusat penyelamatan

satwa Gadog, Ciawi, Bogor. Zoo

Indonesia 2009. 18(1):33-40.

Yasaningthias G. 2010. Aktivitas

Makan, Kuantitas dan Kualitas

Pakan pada Bekantan (Nasalis larvatus) yang Diberi Berbagai

Jenis Pakan di Taman Safari Indonesia.Departemen Biologi Fakultas Matematika ilmu Pengetahuan Alam Institut

Pertanian Bogor.Bogor. 